\title{
Truncating mutations of PPM1D are found in blood DNA samples of lung cancer patients
}

\author{
A Zajkowicz ${ }^{1}$ D Butkiewicz ${ }^{1}$, A Drosik ${ }^{2,3}$, M Giglok² ${ }^{2}$ R Suwiński ${ }^{2}$ and M Rusin*,1 \\ ${ }^{1}$ Center for Translational Research and Molecular Biology of Cancer, Maria Skłodowska -Curie Memorial Cancer Center and \\ Institute of Oncology, Gliwice Branch, 44-101 Gliwice, Poland; ${ }^{2} / l$ Clinic of Radiotherapy and Chemotherapy, Maria Skłodowska- \\ Curie Memorial Cancer Center and Institute of Oncology, Gliwice Branch, 44-101 Gliwice, Poland and ${ }^{3}$ Department of Clinical \\ Oncology, Maria Sktodowska-Curie Memorial Cancer Center and Institute of Oncology, Gliwice Branch, 44-101 Gliwice, Poland
}

Background: PPM1D (WIP1) negatively regulates by dephosphorylation many proteins including p53 tumour suppressor. The truncating mutations (nonsense and frameshift) in exon 6 of PPM1D were found recently in blood cells of patients with breast, ovarian or colorectal cancer. These mutants code for gain-of-function PPM1D with retained phosphatase activity. Their significance in carcinogenesis is unknown.

Methods: The exon 6 of PPM1D was sequenced in blood DNA of 543 non-small-cell lung cancer patients (NSCLC). The functional significance of selected PPM1D alterations (Arg458X, Lys469Glu) was compared with the wild-type gene and examined by recombinant DNA techniques, immunoblotting and luciferase reporter assays.

Results: The frameshift mutations were found in five NSCLC patients (5/543; 0.92\%), all of them had squamous cell carcinomas $(5 / 328 ; 1.5 \%)$. All patients with the mutations were exposed, before the blood collection, to the DNA damaging agents as a part of chemotherapeutic regimen. Functional tests demonstrated that truncating mutation Arg458X causes enhancement of dephosphorylation activity of PPM1D toward serine 15 of p53, whereas Lys469Glu version is equivalent to the wild-type. Neither version of PPM1D (wild-type, Arg458X, Lys469Glu) significantly modulated the ability of p53 to transactivate promoters of the examined p53-target genes (BAX and MDM2).

Conclusions: The truncating mutations of PPM1D are present in blood DNA of NSCLC patients at frequency similar to percentage determined for ovarian cancer patients. Our findings raise a question if the detected lesions are a result of chemotherapy.

The germline mutations of TP53 gene increase the risk of various cancers (McBride et al, 2014). The germline mutations of components of p53 signalling system (e.g., ATM) also modulate cancer risk (Shiloh, 2003). The kinase coded by ATM participates directly in activation of p53 by phosphorylating its serine 15 (Banin et al, 1998; Canman et al, 1998). This phosphate can be removed by a phosphatase coded by PPM1D (WIP1) gene (Lu et al, 2005). WIP1 also dephosphorylates kinases that activate p53 (e.g., ATM, CHK2) (Shreeram et al, 2006; Oliva-Trastoy et al, 2007).

In U-2 OS cells, we detected a nonsense mutation in codon 458 of PPM1D (Arg458X). Initially, the functional significance of this mutation was unknown (Zajkowicz et al, 2013). Independently, this mutation was reported by others (Kleiblova et al, 2013). They found similar truncating mutation in another cell line (HCT116) used in studies of $\mathrm{p} 53$. Moreover, truncating mutations of PPM1D were revealed in blood DNA from colorectal cancer patients. The functional experiments demonstrated that the truncating mutations code for hyper-stable WIP1 protein, which induces strong dephosphorylation of Ser15 of p53 and impairs the p53-dependent G1 checkpoint (Kleiblova et al, 2013). The presence of mutant $P P M 1 D$ in normal cells of cancer patients suggests that the mutations were transmitted in germline and contributed to carcinogenesis. However, a paper published earlier demonstrated that the truncating mutations of PPM1D found in blood cells of breast or ovarian cancer patients may result from sequence alterations formed during individual development as a mosaic 
mutations. The mutant DNA sequences constituted only small fraction of DNA samples. Moreover, in patients available for pedigree analysis, the mutations were present neither in parents nor in progeny of probands (Ruark et al, 2013). These authors sequenced the whole coding region of PPM1D in many patients but found that the truncating mutations (either frameshift or nonsense) cluster within the last coding exon of PPM1D (exon 6). Similar mutations of PPM1D were also found by others in leukocytes of ovarian cancer patients (Akbari et al, 2014).

So far, the truncating PPM1D mutations were found in breast, ovarian and colorectal cancer patients (Kleiblova et al, 2013; Ruark et al, 2013; Akbari et al, 2014). The aforementioned observations suggest that at least some of these mutations are mosaic; however, it is plausible that a fraction of them may be genuine germline mutations. We decided to find out whether truncating mutations of PPM1D are present in blood DNA samples from lung cancer patients.

\section{MATERIAL AND METHODS}

Patient characteristics and mutational analysis. All patients were Polish Caucasians treated for non-small-cell lung cancer (NSCLC) in Maria Skłodowska -Curie Memorial Cancer Center and Institute of Oncology, Gliwice Branch. The demographic and clinical data are presented in Table 1. Most of the patients $(87.5 \%)$ were in advanced clinical stage at the diagnosis (stage III-IV), squamous cell carcinoma was found in $328 / 543$ patients $(60.4 \%)$. Radiotherapy or chemo-radiotherapy was the most common treatment. The blood draw was performed before irradiation and usually after chemotherapy. Nearly all patients (94.3\%) had smoking history. The patients gave the written informed consent for the genetic testing, and the study was approved by the institutional Ethics Committee.

The whole blood DNA samples were purified using Genomic Maxi AX column purification kit (A\&A Biotechnology, Gdynia,

Table 1. Characteristics of the NSCLC patients studied

\begin{tabular}{|l|c|}
\hline Total & $543(100 \%)$ \\
\hline Mean age at diagnosis \pm s.d. (range) & $63.3 \pm 9.08(24-84)$ \\
\hline Sex & $128(23.6 \%)$ \\
\hline Female & $415(76.4 \%)$ \\
Male & $328(60.4 \%)$ \\
\hline Histology & $104(19.2 \%)$ \\
\hline Squamous cell carcinoma & $111(20.4 \%)$ \\
Adenocarcinoma & \\
NSCLC-NOS & \\
\hline Clinical stage & $68(12.5 \%)$ \\
\hline I-II & $362(66.7 \%)$ \\
IIIA-IIIB & $113(20.8 \%)$ \\
\hline IV & $31(5.7 \%)$ \\
\hline Smoking status & $512(94.3 \%)$ \\
\hline Never smokers & \\
Ever smokers & $489(90.1 \%)$ \\
\hline Surgery & $54(9.9 \%)$ \\
\hline no & $194(35.7 \%)$ \\
yes & $349(64.3 \%)$ \\
\hline Chemotherapy & $84(15.5 \%)$ \\
\hline no & $459(84.5 \%)$ \\
\hline yes & \\
\hline Radiotherapy & \\
\hline no & \\
yes & \\
\hline Abbreviation: NSCLC =non-small-cell lung cancer. \\
a NSCLC not otherwise specified.
\end{tabular}

Poland). The exon 6 of PPM1D gene was amplified by PCR with AmpliTaq Gold polymerase (Life Technologies, Carlsbad, CA, USA) and the following primers: WIP-P11 TAGTGAATGC ATACCCCGTT (forward), WIP-P12 CAAGCAAGTACAAGGCC AGGA (reverse). The PCR products were prepared for sequencing by treatment with exonuclease I and shrimp alkaline phosphatase (Affymetrix, Santa Clara, CA, USA). The sequencing reaction was performed using BigDye Terminator v.3.1 cycle sequencing kit (Life Technologies) and the forward primer (TCACATGCATAGATTTGTTGAGTTC) located in intron 5. For confirmation of mutation, the PCR product was also sequenced with reverse primer (GTTCAACATCGGCACCAAAT). The sequencing products were analysed on GA3500 genetic analyzer (Applied Biosystems-Life Technologies, Carlsbad, CA, USA). The mutations were confirmed by resequencing of independent PCR product.

For selected DNA samples with mutations, the PCR products were cloned using CloneJet PCR cloning kit (Fermentas-Thermo Fisher Scientific, Waltham, MA, USA). The bacterial colonies were resuspended in $20 \mu \mathrm{l}$ of TE buffer, boiled and one microlitre of the cleared lysate was used as template. Polymerase chain reaction and sequencing that were performed according to protocol used for genomic DNA.

Preparation of plasmids. The p53-responsive promoters of $B A X$ and MDM2 genes were cloned into pGL3-Basic reporter vector coding for firefly luciferase (Promega, Madison, WI, USA). The plasmid with SmaI-SacI fragment of $B A X$ gene promoter (Miyashita and Reed, 1995) was a kind gift from Dr. Curtis C. Harris (National Cancer Institute, NIH, Bethesda, MD, USA). The human MDM2 promoter 2 containing two p53-responsive elements (Zauberman et al, 1995) was amplified by PCR from genomic DNA sample using primers: TTTTGCTAGCCTTTGTG CGGTTCGTGG, TTTTAAGCTT GCCTACAAGGAAAAAAAAGACA with the attached restriction sites for, respectively, NheI and HinDIII (underlined). We ligated the amplified DNA into NheI and HinDIII sites of pGL3-Basic plasmid. The inserted DNA was sequenced to ensure that the clone contained no mutations introduced by PCR.

The cDNA coding for wild-type and mutant (codon 458:CGA > TGA) WIP1 cDNA was cloned from RNA sample from U-2 OS cells. The total RNA was reversely transcribed with MuLV reverse transcriptase and random hexamers (Life Technologies). The cDNA was amplified with Proof Start polymerase (Qiagen, Hilden, Germany) using primers: WIP-SQ1 AACAATAGTTGGCCGGCGAG and WIP-SQ12 GTTCAACA TCGGCACCAAAT amplifying the whole coding sequence of PPM1D. Subsequently, the nested PCR was performed with Proof Start polymerase and primers: WIP-CLO1 and WIP-CLO2, which are nested in the first PCR product. The WIP-CLO1 primer TTTTAAGCTTATGGCGGGGCTGTACTCG contains the HinDIII restriction site (underlined) and is complimentary to the beginning of WIP1 open reading frame (ORF, bold). The WIP-CLO2 primer TTTTTCTAGATCAGCAAACACAAACAGTTTTC contains the XbaI site (underlined), the STOP codon and the end of WIP1 ORF (bold). The PCR product was cloned into pJET1.2/blunt using CloneJET PCR cloning kit (FermentasThermo Fisher Scientific). The clones with wild-type or mutant (codon 458) sequences were identified. Subsequently, the cloned PCR products were cut out from the pJET1.2/blunt vector with HinDIII and $\mathrm{XbaI}$ and were ligated into these restriction sites of pcDNA3.1 + expression vector (Invitrogen-Life Technologies, Carlsbad, CA, USA) creating plasmids pcDNA3.1-WIP1-wild-type and pcDNA3.1-WIP1-mut-458.

The DNA fragment containing exon 6 with the substitution in codon 469 (AAA > GAA) was amplified by PCR from genomic DNA of the heterozygous individual using primers: WIP-P11 (see above) and WIP-CLO2. The PCR product was cloned into 
pJET1.2/blunt using CloneJET PCR cloning kit. The clones containing the codon 469 nucleotide substitution were identified. The beginning of WIP1 exon 6 contains BamHI site. The BamHIXbaI fragment of pcDNA3.1-WIP1-wild-type plasmid was replaced by BamHI-XbaI fragment with codon 469 substitution cloned in pJET1.2/blunt. The resulting plasmid was named pcDNA3.1-WIP1-mut469.

Analysis of p53 expression and phosphorylation. The NCIH1299 cells (ATCC, Manassas, VA, USA) and SAOS-2 cells (European Collection of Cell Cultures, Salisbury, UK) do not express endogenous p53 protein. They were grown at $37^{\circ} \mathrm{C}, 5 \%$ $\mathrm{CO}_{2}$, in DMEM medium (Sigma-Aldrich, St Louis, MO, USA) supplemented with $10 \%$ foetal bovine serum (Gibco-Life Technologies, Carlsbad, CA, USA) and penicillin/streptomycin (Sigma-Aldrich). The NCI-H1299 cells were transfected with FuGene6 (Promega), whereas SAOS-2 cells were transfected with Fugene HD (Active Motif, La Hulpe, Belgium) according to manufacturer's protocol. Some transfected SAOS-2 cells were treated with $1 \mu \mathrm{M}$ camptothecin (Calbiochem-Merck, Darmstadt, Germany, the stock solution $4 \mathrm{mM}$ in DMSO), a topoisomerase I inhibitor strongly activating p53 (Jaks et al, 2001). The wild-type p53 was expressed from pC53-SN3 plasmid, which was a gift from Dr. Bert Vogelstein and Dr. Kenneth W. Kinzler from Johns Hopkins University, Baltimore, MD, USA (Baker et al, 1990). The null-control cells were transfected with empty expression vector $(\mathrm{pcDNA3} .1+)$. The negative control cells were transfected with p53 expression vector and empty pcDNA3.1 + plasmid. The experimental cells were transfected with p53 expression plasmid and the plasmid expressing wild-type or mutant forms of WIP1.

The SAOS-2 were seeded on two 6-well plates in $2 \mathrm{ml}$ of medium. The transfection mixture for one well consisted of $6 \mu \mathrm{l}$ of Fugene HD and $2 \mu \mathrm{g}$ of DNA in $100 \mu \mathrm{l}$ of growth medium without serum and antibiotics. The weight ratio of pC53-SN3 plasmid to WIP1 plasmid was $1: 1$. After $24 \mathrm{~h}$, the medium with transfecting reagents was removed, and the cells were washed with fresh medium. Subsequently, the cells on one plate were supplemented with medium containing $1 \mu \mathrm{M}$ camptothecin and the cells on the other plate were supplemented with medium containing $0.025 \%$ DMSO. After 24-h incubation, the cells were harvested by trypsinisation, washed with $\mathrm{PBS}$, and the cell pellets were frozen on dry ice and stored at $-70{ }^{\circ} \mathrm{C}$.

The NCI-H1299 cells were seeded on 6-well plate. The ratio of FuGene6 to DNA was $3 \mu \mathrm{l}: 1,2 \mu \mathrm{g}$. The ratio of p53:WIP1 plasmids was $1: 1$. After $48 \mathrm{~h}$, the cells were harvested and stored as SAOS-2 cells.

The preparation of protein extracts in IP buffer and other steps of western blotting was performed as described before (Zajkowicz et al, 2013). The following antibodies were used in the detection step: anti-p53 (DO1, Santa Cruz Biotechnology_SCBT, Dallas, TX, USA), anti-phospho-p53 at Ser 15 (rabbit polyclonal antibody from Cell Signaling Technology, Danvers, MA, USA), anti-p21 (F-5, SCBT), anti-MDM2 (HDM2-323, SCBT), anti-HSC70 (B-6, SCBT), anti-WIP1 (H-300, SCBT).

Luciferase reporter assays. The NCI-H1299 cells were seeded on 12-well plates. The next day, the cells were transfected, according to the manufacturer's protocol, using FuGene6 (1,2 $\mu$ l per well) with the combination of the reporter vector coding for firefly luciferase under the control of either $B A X$ or MDM2 promoters $(0.12 \mu \mathrm{g})$, the expression vector pC53-SN3 (p53 plasmid, $0.18 \mu \mathrm{g}$ ) and the expression vector $(0.3 \mu \mathrm{g})$ coding for wild-type or mutant cDNA of WIP1 (PPM1D). In negative control, the p53 and WIP1 plasmids were replaced by empty pcDNA3.1 + so the amount of DNA in transfection mixtures was kept constant $(0,6 \mu \mathrm{g})$. The transfection mixture also contained pRL-TK vector $(0.012 \mu \mathrm{g})$ coding for Renilla sp. luciferase under the control of the herpes simplex virus thymidine kinase promoter that served as an internal control. After $48 \mathrm{~h}$ from the start of transfection, the cells were washed with PBS and lysed with passive lysis buffer from Dual Luciferase Reporter Assay system (Promega) that was also used to measure the firefly and Renilla $s p$. luciferase activities. The firefly luciferase activity was normalised to Renilla sp. luciferase activity. Each transfection was performed in triplicate in three independent experiments.

\section{RESULTS}

The coding region of exon 6 of PPM1D was sequenced in DNA samples isolated from blood of 543 NSCLC patients. In five patients $(0.92 \%)$, we detected the electropherogram pattern consistent with the deletion/insertion mutations. In three cases, the mutation constituted a relatively large part of DNA sample. It enabled the precise identification of the deleted nucleotide (Figure 1). We cloned the relevant PPM1D PCR products from two patients showing similar intensities of wild-type and mutant reads on electropherograms (Figure 1, case no. 189 and case no. 522). We sequenced individual clones (derived from single molecules of PCR products-the essence of cloning in bacteria) and counted clones with wild-type and mutant sequences. This gave us better estimation of proportion of wild-type versus mutant sequence in DNA sample than the 'height' of electropherogram peaks. For case no. 522 (c.1288delG), we have sequenced 41 clones; $31(76 \%)$ had wild-type sequence whereas $10(24 \%)$ had mutant sequence. This proportion significantly differs from 50\% versus

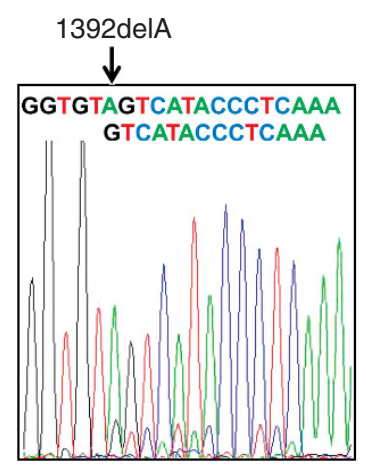

Case: 208

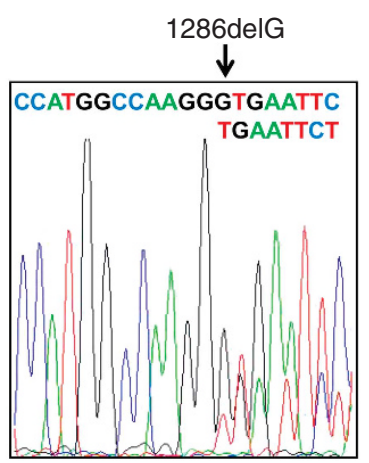

Case: 522

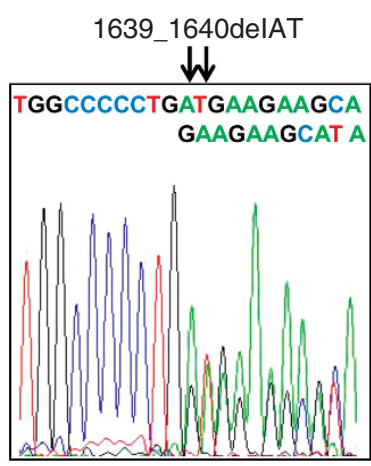

Case: 189

Figure 1. Sequencing electropherograms of PPM1D showing localisation of frameshift mutations found in DNA samples isolated from blood of NSCLC patients. The strings of letters illustrate superimposed sequences that start from the site of deletion (arrows). 
$50 \%$ ratio expected for the germline mutation ( $\chi^{2}$ test, $P=0.03$ ). Thus, this indicates that case no. 522 has mosaic mutation of PPM1D and that the mutant cells constitute a large proportion of peripheral white blood cell population. Assuming that the white blood cells with mutant PPM1D harbour wild-type allele on the other chromosome and taking into account that mutant sequence constitutes about one quarter of DNA sample, it can be estimated that cells with mutant PPM1D make up about $50 \%$ of cell population. For case no. 189, we have sequenced 37 clones finding $25(68 \%)$ with wild-type sequence and 12 (32\%) with mutant one. The predominance of wild-type sequence suggests the mosaic nature of mutation, however, the proportion does not significantly differ from the expected $50 \%$ versus $50 \%$ ratio ( $\chi^{2}$ test $P=0.198$ ); hence, we cannot formally reject the hypothesis that case no. 189 has germline mutation, although this possibility is less likely than mosaicism.

In two cases, the mutation constituted small fraction of DNA sample (consistent with the mosaic nature of mutation) and only the approximate localisation of mutant position was possible. In these cases, we also cloned PCR product in bacterial plasmids. We
Putative mutation, case 304
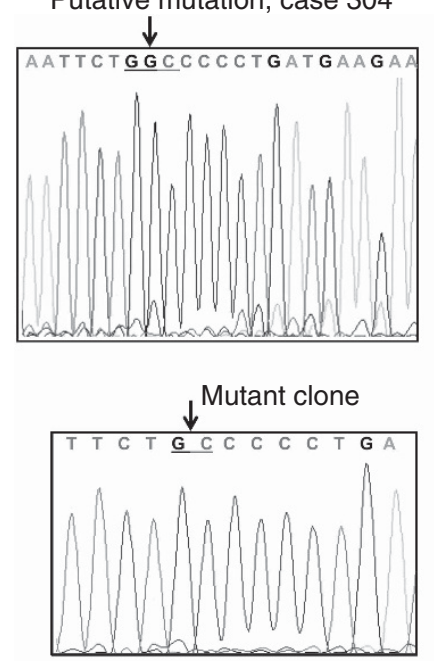

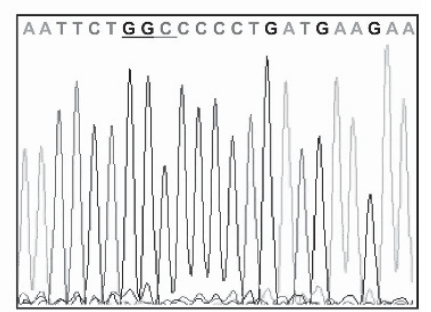

Wild-type clone

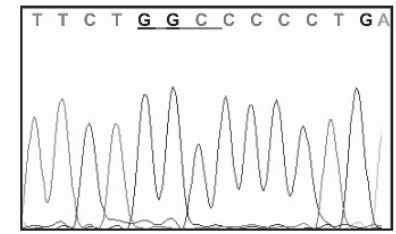

Wild-type genomic sequence

Figure 2. Sequencing electropherograms of PPM1D from genomic DNA samples (upper panels) and from bacterial clones (lower panels) derived from cloned PCR product of amplified exon 6 of case 304 whose genomic electropherogram showed evidence of putative mutation. have sequenced DNA from 8 to 12 clones to detect the one with mutation what allowed for precise identification of the sequence change (Figure 2, Table 2).

Out of five mutations detected by us, four were 1-base pair (bp) deletions, whereas one was 2-bp deletion, therefore the mutations generated frameshifts resulting in stop codons at or very close to the mutation sites (Table 2). All mutations were found in patients with squamous cell carcinomas (SCC), hence the frequency of PPM1D mutations in this histological type of NSCLC is $1.5 \%$ (5/328). Table 2 describes the clinical characteristics of five patients with mutation. No apparent differences between clinical characteristics of these patients and the patients without mutation can be found, except for relatively high age at the diagnosis of five individuals of interest (mean 69 years). All patients with mutations underwent chemotherapy before the blood draw (Table 2). As for the patients without mutations, only 68 cases had chemotherapy after the blood draw. For the remaining 246 cases, which did not harbour mutations and for which the detailed dates of treatment were available, the mean time from the end of chemotherapy to the blood draw was 15.3 weeks (standard deviation \pm 36.3 weeks, median 6.1 weeks, range $0-363$ weeks). The difference in frequency of truncating mutations between SCC and adenocarcinomas is not due to more frequent use of chemotherapy in SCC, because SCC cases less frequently underwent chemotherapy than adenocarcinoma cases $\left(197 / 328,60 \%\right.$ versus $79 / 104,76 \% ; P=0.005$ by $\chi^{2}$ test).

The frequency of truncating mutations found in our group of cancer patients $(5 / 543)$ is higher than the frequency found in the blood of non-cancer controls by other researchers (1/5861 in Ruark et al, 2013 and 0/450 in Kleiblova et al, 2013). Thus, these mutations are clearly cancer-related.

The sequencing of coding fragment of exon 6 also revealed five different single nucleotide substitutions. Four of them generate amino acid substitutions and one is a silent mutation (Table 3 ). Three variants have been identified by others and are listed in the short nucleotide polymorphisms database http://www.ncbi.nlm. nih.gov/snp. Two of the nucleotide substitutions are reported here for the first time (Table 3).

To the best of our knowledge, the functional significance of these rare $P P M 1 D$ variants with amino acid substitutions was not examined. It is not known whether they are functionally neutral or modulate the activity of WIP1 phosphatase. We have selected one (469:AAA- > GAA) for functional study. It was chosen because it changes amino acid with basic side chain to the amino acid with acidic side chain (Lys469Glu). As a positive control, we used the previously detected mutant version of PPM1D from U-2 OS cells (R458X) (Zajkowicz et al, 2013). We wanted to confirm and extend the results of others (Kleiblova et al, 2013) who showed that this

Table 2. Characteristics of the patients with exon 6 PPM1D truncating mutations (frameshifts)

\begin{tabular}{|c|c|c|c|c|c|c|c|c|c|c|c|c|c|}
\hline Case ID & Mut & $\begin{array}{c}\text { Mut } \\
\text { in } \\
\text { codon }\end{array}$ & $\begin{array}{l}\text { STOP } \\
\text { in } \\
\text { codon }\end{array}$ & Sex & $\begin{array}{c}\text { Age at } \\
\text { diagnosis } \\
\text { (years) }\end{array}$ & Stage & $\begin{array}{c}\mathrm{ChT} \\
\text { regimen }\end{array}$ & $\begin{array}{c}\text { Number } \\
\text { of } \mathrm{ChT} \\
\text { cycles }\end{array}$ & $\begin{array}{c}\text { Clinical } \\
\text { response } \\
\text { to } \mathrm{ChT}\end{array}$ & $\begin{array}{l}\text { End of } \\
\text { ChT to } \\
\text { blood } \\
\text { draw }\end{array}$ & $\begin{array}{c}\text { Radiation } \\
\text { dose }\end{array}$ & $\begin{array}{c}\text { Survival } \\
\text { after } \\
\text { diagnosis } \\
\text { (months) }\end{array}$ & $\begin{array}{l}\text { Family } \\
\text { history of } \\
\text { cancer }\end{array}$ \\
\hline 522 & c.1288delG & 430 & 430 & M & 70 & IV & cisPt + Eto & 2 & $\begin{array}{c}\text { Progressive } \\
\text { disease }\end{array}$ & 17 weeks & $<60 \mathrm{~Gy}$ & 7.1 & None \\
\hline 208 & c.1392delA & 464 & 482 & M & 69 & IIIB & $\operatorname{cisPt}+\mathrm{Vin}$ & 4 & $\begin{array}{l}\text { Stable } \\
\text { disease }\end{array}$ & 4 weeks & $\geqslant 60 \mathrm{~Gy}$ & 11.0 & $\begin{array}{c}\text { Brother } \\
\text { (colorectal ca.) }\end{array}$ \\
\hline 304 & c.1631delG & 544 & 546 & $\mathrm{~F}$ & 62 & IIIA & cisPt + Eto & 3 & $\begin{array}{c}\text { Partial } \\
\text { response }\end{array}$ & 5 weeks & $\geqslant 60 \mathrm{~Gy}$ & $42.3^{a}$ & $\begin{array}{l}\text { Brother } \\
\text { (lung ca.) }\end{array}$ \\
\hline 9608 & c.1639delA & 547 & 547 & $M$ & 71 & IIIB & $\operatorname{cisPt}+\mathrm{Vin}$ & 4 & $\begin{array}{l}\text { Partial } \\
\text { response }\end{array}$ & 2 weeks & $\geqslant 60 \mathrm{~Gy}$ & 15.4 & None \\
\hline 189 & c.1639_1640delAT & 547 & 550 & $\mathrm{~F}$ & 75 & IV & $\operatorname{cisPt}+\mathrm{Vin}$ & 4 & $\begin{array}{l}\text { Stable } \\
\text { disease }\end{array}$ & 18 weeks & $<60 \mathrm{~Gy}$ & 10.2 & $\begin{array}{l}\text { Brother } \\
\text { (unknown) }\end{array}$ \\
\hline \multicolumn{14}{|c|}{$\begin{array}{l}\text { Abbreviations: } \mathrm{ChT}=\text { chemotherapy; cisPt }=\text { cisplatin; Eto = Etoposide; Mut = mutation; Vin = vinorelbine. All patients with mutations were smokers and were diagnosed with squamous cell } \\
\text { carcinoma } \\
{ }^{a} \text { Survival from diagnosis to last visit }(31.01 .2014) \text {. }\end{array}$} \\
\hline
\end{tabular}


Table 3. Nucleotide substitutions found in coding sequence of exon 6 of PPM1D

\begin{tabular}{|c|c|c|c|c|c|}
\hline Mutation & Codon number & Codon change & $\begin{array}{l}\text { Amino acid } \\
\text { substitution }\end{array}$ & SNP number & $\begin{array}{l}\text { Number of } \\
\text { carriers (\%) }\end{array}$ \\
\hline c. $1379 \mathrm{~A}->\mathrm{C}$ & 460 & AAET->ACET & Asn->Thr & none & $1(0.18 \%)$ \\
\hline c. $1405 \mathrm{~A}->\mathrm{G}$ & 469 & $\underline{A A A}->\underline{G A A}$ & Lys-> Glu & rs61756416 & $1(0.18 \%)$ \\
\hline c. $1486 \mathrm{~A}->\mathrm{G}$ & 496 & $\underline{\mathrm{ATTT}}->\underline{\mathrm{G} T T}$ & Ile-> Val & rs35491690 & $2(0.36 \%)$ \\
\hline c. $1525 \mathrm{G}->\mathrm{C}$ & 509 & $\underline{\text { GAC- }}>\underline{\mathrm{C} A C}$ & Asp-> His & rs368204511 & $1(0.18 \%)$ \\
\hline c. $1716 \mathrm{~A}->\mathrm{G}$ & 572 & CGA->CGG & Arg->Arg & none & $1(0.18 \%)$ \\
\hline
\end{tabular}

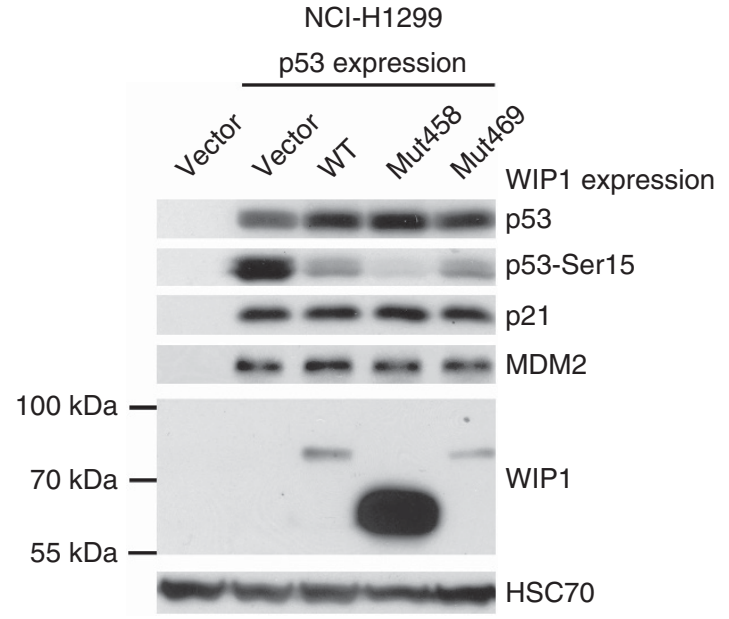

Figure 3. Expression of total p53, p53 phosphorylated on Ser15 and expression of $\mathrm{p} 21, \mathrm{MDM} 2$ and WIP1 proteins in $\mathrm{NCl}-\mathrm{H} 1299$ cells. The level of HSC70 is a loading control. This cell line does not express endogenous p53. The lysate in lane 1 is from cells transfected with empty vector. Other cells were co-transfected with vector expressing p53 and either empty vector or vector expressing various forms of WIP1 protein (Mut458-Arg458X, Mut469-Lys469Glu) whose molecular weight can be estimated by comparison with markers shown on the left. The lysates were prepared after 48-h transfection.

mutation (R458X) codes for the molecule, which is more stable and accumulates to much higher level than the wild-type protein.

We have created expression vectors coding for wild-type or mutant versions of WIP1 protein (Mut458, Mut469). Subsequently, the vectors coding for the selected forms of WIP1 were transfected to NCI-H1299 cells together with the expression vector coding for wild-type p53. The recombinant WIP1 is expressed from the vectors as shown on immunoblot (Figure 3). Expectedly, the Mut458 codes for WIP1 with lower molecular weight. The amount of the protein with Lys469Glu substitution is similar to the amount of wild-type protein. In strong contrast, the amount of the truncated protein expressed from Mut458 vector is significantly higher. This is consistent with the observations made by others (Kleiblova et al, 2013) who showed that this mutant protein is more stable than the wild-type version. In our experiment, the expression of any form of WIP1 lowered the level of p53 with phosphorylated serine 15 without changing the total amount of p53 (Figure 3). The Arg458X causes enhancement of this dephosphorylation activity, whereas Lys469Glu is equivalent to the wild-type sequence. This is consistent with the observations that the truncated WIP1 codes for gain-of-function mutants (Kleiblova et al, 2013; Ruark et al, 2013). Unexpectedly, the major differences in the phosphorylation status of p53 Ser15 did not influence the ability of ectopic p53 to activate the expression of endogenous targets of $\mathrm{p} 53$ - the genes coding for p21 or MDM2 proteins (Figure 3 ). Thus, in this experimental system, the effect of

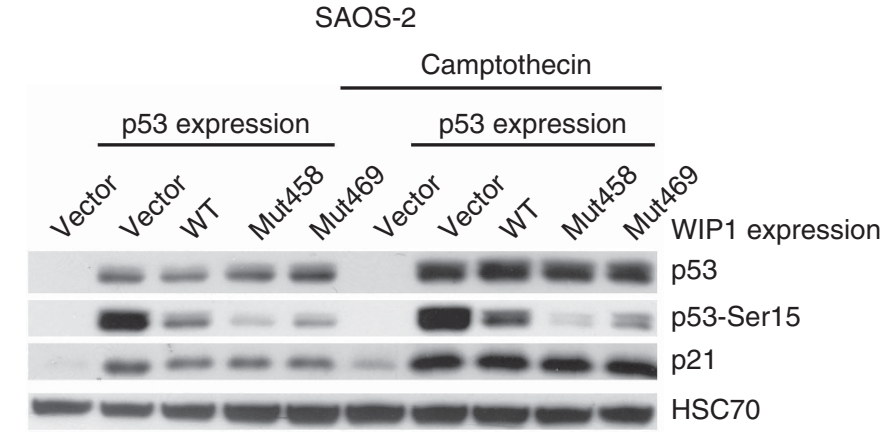

Figure 4. Expression of total p53, p53 phosphorylated on Ser15 and expression of p21 in SAOS-2 cells. The lysates in lanes 1 and 6 are from cells transfected with empty vector. Other cells were co-transfected with vector expressing p53 and either empty vector or vector expressing various forms of WIP1 protein. After 24-h transfection, the cells were either mock-treated or incubated with $1 \mu \mathrm{M}$ camptothecin for $24 \mathrm{~h}$.

Arg458X on enhancing dephosphorylation does not influence the transactivation activity of $\mathrm{p} 53$ on its target genes. A similar experiment was performed on a different cell line, which also does not express p53 protein (SAOS-2 osteosarcoma cell line). In this case, we have additionally treated the cells with camptothecin, which is a strong activator of p53 (Figure 4). As expected, the camptothecin treatment induced stronger accumulation of total p53 and induced stronger expression of endogenous p21 protein. Expression of any form of WIP1 diminished the phosphorylation of Ser 15 of p53 in both treated and untreated cells. Expression of Arg458X induced the strongest dephosphorylation of p53. Similar to previous experiment, the Ser 15 phosphorylation status of p53 did not modulate the expression of endogenous $\mathrm{p} 21$. To further examine the influence of various forms of WIP1 on the ability of p53 to transactivate genes, we used another experimental system employing the reporter vectors containing the p53-responsive gene promoters. We selected promoters from $B A X$ and MDM2 genes, which in our experimental system, are activated 15- and 200-fold, respectively, by p53 expressed from the co-transfected vector in NCI-H1299 cells (Figure 5). The co-expression of WIP1 did not significantly modulate the ability of p53 to transactivate $B A X$ or MDM2 promoters. Thus, the observations made using different experimental settings suggest that very strong expression of mutant WIP1, which clearly has the ability to diminish p53 phosphorylation on Ser15, does not measurably influence the ability of p53 to regulate the expression of its target genes. Moreover, we conclude that WIP1 protein with Lys469Glu substitution does not significantly differ from wild type in our experiments.

\section{DISCUSSION}

This is the first report on PPM1D mutations in blood DNA of NSCLC patients. Moreover, the truncating mutations detected by 

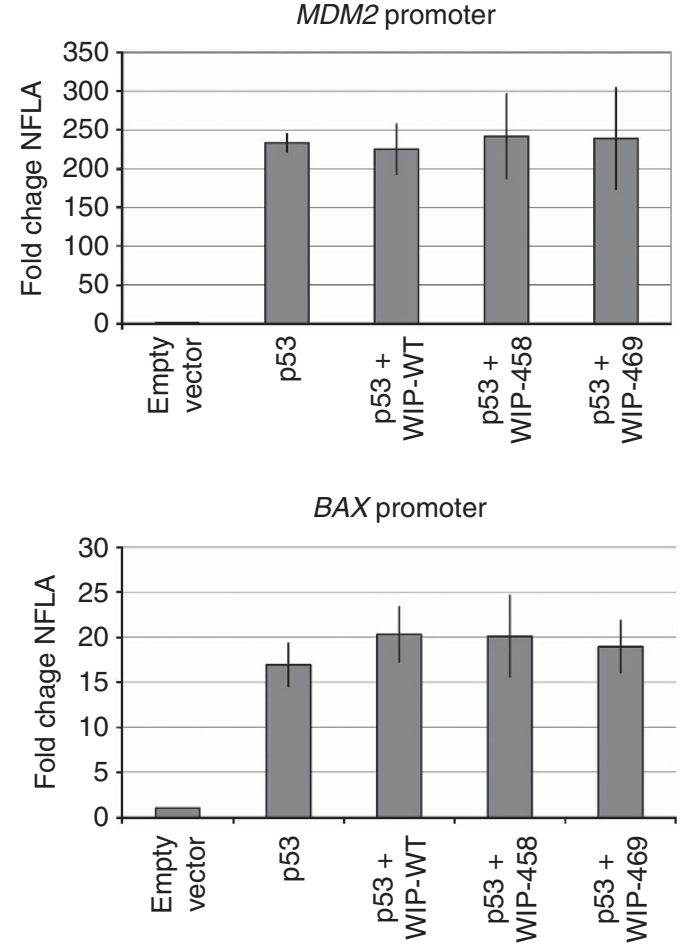

Figure 5. The fold change of the normalised firefly luciferase activity (NFLA) in NCl-H1299 cells. Normalised firefly luciferase activity was calculated by dividing firefly luciferase activity by the Renilla sp. luciferase activity. The cells were co-transfected as described in the Materials and Methods with reporter vectors (MDM2 or BAX) with or without the pC53-SN3 (p53-plasmid) and the vectors expressing various forms of WIP1. The NFLA value in cells transfected with reporter vector and empty plasmid was set as 1 . The graph shows means and standard deviations from three independent experiments performed in triplicate. The expression of either wild-type (WT) or mutant WIP1 does not significantly modulate the strong stimulatory effect of p53 on MDM2 or BAX promoters ( $P>0.05$ by Student $t$-test).

us were not reported in three papers on PPM1D alterations found in blood cells of breast, ovarian or colorectal cancer patients (Kleiblova et al, 2013, Ruark et al, 2013; Akbari et al, 2014). The frequency of NSCLC cases with mutations $(0.92 \%)$ is higher than the frequency of colorectal cancer patients $(0.66 \%)$ (Kleiblova et al, 2013 ) and breast cancer patients $(0.26 \%)$, but very similar to the frequency of ovarian cancer patients (1.07\%) (Ruark et al, 2013). Another study reported $1.5 \%$ of ovarian cancer cases with truncating mutations of PPM1D (Akbari et al, 2014). The PPM1D truncating mutations arising somatically were recently found in brainstem gliomas (Zhang et al, 2014).

So far, more than 30 truncating mutations of PPM1D have been published, however, the functional significance of only some of them was examined. The mutations that we and others have detected are located within the mutation cluster region identified in PPM1D by Ruark et al. (2013). The gain-of-function nature of the following mutations was assessed and confirmed: c.1384C $>\mathrm{T}$ (p.Q462X), c.1420delC (Ruark et al, 2013), c.1349delT (p.450X), c.1372C > T (p.R458X) (Kleiblova et al, 2013). It is assumed that all truncating mutations in the mutation cluster region of PPM1D are of gain-of-function type. This assumption may be verified in the future, for example, by simple tests that we have performed for the mutation (p.R458X) found in U-2 OS cells (Figure 3).

In three cases reported in our study, the mutant sequence constituted a small fraction of DNA sample what is consistent with mosaic nature of the mutations. However, in two cases, the electropherogram peaks of wild-type and mutant sequences exhibited similar intensity (Figure 1) indicating that a large proportion of blood cells contain the mutant version of PPM1D gene (wild-type version on one chromosome and the mutant on the other). Thus, in these two cases, we found either a germline mutation or mosaicism. However, more precise estimation of proportion of mutant and wild-type sequence (see Results) performed by cloning of PCR product strongly suggests mosaicism.

We found no evidence that hyperactive WIP1 can modulate the ability of p53 to activate the promoters either of endogenous genes or the promoters cloned in reporter vectors (Figures 3-5). Although p53 phosphorylation is correlated with its activation, many studies showed that p53 can be activated regardless of its phosphorylation status (reviewed by Kruse and Gu, 2009). Specifically, Fuchs et al. (1995) demonstrated that Ser15 phosphorylation mutant retains transcription activity and ability to suppress cell growth. Our observations apparently contrasts with the data published by others (Kleiblova et al. 2013) who showed that knockdown of WIP1 (either its mutant or wild-type form) promotes the expression of p21 - the product of p53 target gene. We have also noticed in our previous experiments that downregulation of WIP1 with shRNA in U-2 OS cells promotes the expression of p21 in untreated cells (Zajkowicz et al, 2013). We speculate that the inability of hyperactive WIP1 to modulate the expression of p53 target genes results from the high expression level of p53 from the transfected plasmid. Our approach is apparently suitable for detection of the influence of WIP1 on the phosphorylation status of ectopic p53, but the amount of ectopic p53 may be too high for detection of the modulating effect of Ser15 phosphorylation on the ability of p53 to regulate the expression of target genes. It is also plausible that p53 is not the only target for the hyperactive, gain-of-function, truncated versions of WIP1 protein. WIP1 can dephosphorylate other proteins, including components of the base excision repair, what is associated with decreased activity of this DNA repair system (Lu et al, 2004). Thus, hyperactive WIP1 may increase the mutation rate and by doing so, its mosaic/germline mutations may promote the formation of cancer.

One of the major questions arising from our study is whether the detected mutations were induced by chemotherapy. All patients with the truncating mutations were exposed, before the blood collection, to the DNA-damaging agents as a part of chemotherapeutic regimen (Table 2). There are numerous examples showing that chemotherapeutic agents promote mutagenesis and the formation of therapy-induced cancers, for example, radiotherapy for Hodgkin lymphoma significantly increases risk of lung cancer, and the risk of developing leukaemia is elevated after platinumbased chemotherapy for testicular or ovarian cancer. Usually the latency between therapy and the formation of secondary cancer is as long as several or more years (see review by Allan and Travis, 2005). In the case of our group of patients, the latency between the chemotherapy and the detection of the PPM1D mutations in white blood cells was relatively short-several months. At this moment, we cannot judge whether this is enough time to generate and expand the mutant clone of white blood cells. Another question arising from our study is whether the cells with PPM1D mutations were selected by chemotherapy owing to their potentially increased apoptosis resistance caused by attenuation of p53 activity. These questions cannot be answered without further studies, which must be designed in a way that will elucidate whether the mutations are induced/selected by chemotherapy.

In conclusion, our study revealed that truncating mutations of PPM1D are present in blood DNA of $0,9 \%$ NSCLC patients. The mutations are found exclusively in cases with SCC. Consistent with previous findings, the mutant form R458X found in U-2 OS cell line accumulates in cells to significantly higher amount than the wild-type form and strongly reduces the phosphorylation of p53 on Ser15. The variant with Lys469Glu amino acid substitution is equivalent to wild type in our experiments. 


\section{ACKNOWLEDGEMENTS}

This work was supported by grants no. NN401-597240, 2012/05/B/ NZ5/01905, 2013/11/B/NZ5/03190 from National Science Centre, Poland. We appreciate technical assistance from Mrs. Iwona Matuszczyk.

\section{CONFLICT OF INTEREST}

The authors declare no conflict of interest.

\section{REFERENCES}

Akbari MR, Lepage P, Rosen B, McLaughlin J, Risch H, Minden M, Narod SA (2014) PPM1D mutations in circulating white blood cells and the risk for ovarian cancer. J Natl Cancer 106: djt323.

Allan JM, Travis LB (2005) Mechanisms of therapy-related carcinogenesis. Nat Rev Cancer 5: 943-955.

Baker SJ, Markowitz S, Fearon ER, Willson JK, Vogelstein B (1990) Suppression of human colorectal carcinoma cell growth by wild-type p53. Science 249: 912-915.

Banin S, Moyal L, Shieh S, Taya Y, Anderson CW, Chessa L, Smorodinsky NI, Prives C, Reiss Y, Shiloh Y, Ziv Y (1998) Enhanced phosphorylation of p53 by ATM in response to DNA damage. Science 281: 1674-1677.

Canman CE, Lim DS, Cimprich KA, Taya Y, Tamai K, Sakaguchi K, Appella E, Kastan MB, Siliciano JD (1998) Activation of the ATM kinase by ionizing radiation and phosphorylation of p53. Science 281: 1677-1679.

Fuchs B, O'Connor D, Fallis L, Scheidtmann KH, Lu X (1995) p53 phosphorylation mutants retain transcription activity. Oncogene 10: 789-793.

Jaks V, Jõers A, Kristjuhan A, Maimets T (2001) p53 protein accumulation in addition to the transactivation activity is required for p53-dependent cell cycle agrest after treatment of cells with camptothecin. Oncogene 20: 1212-1219.

Kleiblova P, Shaltiel IA, Benada J, Ševčík J, Pecháčková S, Pohlreich P, Voest EE, Dundr P, Bartek J, Kleibl Z, Medema RH, Macurek L (2013) Gain-of-function mutations of PPM1D/Wip1 impair the p53-dependent G1 checkpoint. J Cell Biol 201: 511-521.

Kruse JP, Gu W (2009) Modes of p53 regulation. Cell 137: 609-622.

Lu X, Bocangel D, Nannenga B, Yamaguchi H, Appella E, Donehower LA (2004) The p53-induced oncogenic phosphatase PPM1D interacts with uracil DNA glycosylase and suppresses base excision repair. Mol Cell 15: 621-634.

Lu X, Nannenga B, Donehower LA (2005) PPM1D dephosphorylates Chk1 and p53 and abrogates cell cycle checkpoints. Genes Dev 19: 1162-1174.
McBride KA, Ballinger ML, Killick E, Kirk J, Tattersall MH, Eeles RA, Thomas DM, Mitchell G (2014) Li-Fraumeni syndrome: cancer risk assessment and clinical management. Nat Rev Clin Oncol 11: 260-271.

Miyashita T, Reed JC (1995) Tumor suppressor p53 is a direct transcriptional activator of the human bax gene. Cell 80: 293-299.

Oliva-Trastoy M, Berthonaud V, Chevalier A, Ducrot C, Marsolier-Kergoat MC, Mann C, Leteurtre F (2007) The Wip1 phosphatase (PPM1D) antagonizes activation of the Chk2 tumour suppressor kinase. Oncogene 26: 1449-1458.

Ruark E, Snape K, Humburg P, Loveday C, Bajrami I, Brough R, Rodrigues DN, Renwick A, Seal S, Ramsay E, Duarte Sdel V, Rivas MA, Warren-Perry M, Zachariou A, Campion-Flora A, Hanks S, Murray A, Ansari Pour N, Douglas J, Gregory L, Rimmer A, Walker NM, Yang TP, Adlard JW, Barwell J, Berg J, Brady AF, Brewer C, Brice G, Chapman C, Cook J, Davidson R, Donaldson A, Douglas F, Eccles D, Evans DG, Greenhalgh L, Henderson A, Izatt L, Kumar A, Lalloo F, Miedzybrodzka Z, Morrison PJ, Paterson J, Porteous M, Rogers MT, Shanley S, Walker L, Gore M, Houlston R, Brown MA, Caufield MJ, Deloukas P, McCarthy MI, Todd JA. Breast and Ovarian Cancer Susceptibility Collaboration; Wellcome Trust Case Control ConsortiumTurnbull C, Reis-Filho JS, Ashworth A, Antoniou AC, Lord CJ, Donnelly P, Rahman N (2013) Mosaic PPM1D mutations are associated with predisposition to breast and ovarian cancer. Nature 493: 406-410.

Shiloh Y (2003) ATM and related protein kinases: safeguarding genome integrity. Nat Rev Cancer 3: 155-168.

Shreeram S, Demidov ON, Hee WK, Yamaguchi H, Onishi N, Kek C, Timofeev ON, Dudgeon C, Fornace AJ, Anderson CW, Minami Y, Appella E, Bulavin DV (2006) Wipl phosphatase modulates ATMdependent signaling pathways. Mol Cell 23: 757-764.

Zajkowicz A, Krześniak M, Matuszczyk I, Głowala-Kosińska M, Butkiewicz D, Rusin M (2013) Nutlin-3a, an MDM2 antagonist and $\mathrm{p} 53$ activator, helps to preserve the replicative potential of cancer cells treated with a genotoxic dose of resveratrol. Mol Biol Rep 40: 5013-5026.

Zauberman A, Flusberg D, Haupt Y, Barak Y, Oren M (1995) A functional p53-responsive intronic promoter is contained within the human $\mathrm{mdm} 2$ gene. Nucleic Acids Res 23: 2584-2592.

Zhang L, Chen LH, Wan H, Yang R, Wang Z, Feng J, Yang S, Jones S, Wang S, Zhou W, Zhu H, Killela PJ, Zhang J, Wu Z, Li G, Hao S, Wang Y, Webb JB, Friedman HS, Friedman AH, McLendon RE, He Y, Reitman ZJ, Bigner DD, Yan H (2014) Exome sequencing identifies somatic gain-offunction PPM1D mutations in brainstem gliomas. Nat Genet 46: 726-730.

This work is published under the standard license to publish agreement. After 12 months the work will become freely available and the license terms will switch to a Creative Commons AttributionNonCommercial-Share Alike 4.0 Unported License. 